\title{
Research on Teaching Model of College Computer Professional English
}

\author{
Weili Chu, Yanmei Meng, Zhengru Xu
}

${ }^{1}$ Qingdao Huanghai University, Qingdao, Shandong, China

\begin{abstract}
Because of the rapid development of computer, new term about IT is emerging. Such new IT original comes from foreign countries and the technical manuals about how to learn such as new IT and how to use its latest development tools in English. It is one of the most important professional skills of college students in computer science. It can help students to study in professional field. It is a very practical skill. In view of the characteristics of computer English courses and the problems in teaching, This paper puts forward some conception of teaching innovation mode from the aspects of optimizing the course content, teaching methods and teaching methods, and linking the computer professional English with other professional courses to achieve the practical application goal, so as to improve the teaching quality of the computer major English course. To stimulate students to the choice of teaching materials to the ability of teachers and other aspects of training to improve, in order to be able to computer professional students to do a good job in English teaching, the real training for the country in line with the needs of the times the computer and English combination of two professionals.
\end{abstract}

Keywords: Computer Professional English, Teaching Mode, Internet Teaching Platform

\section{Theoretical Introduction of Computer Professional English Teaching}

Computer Professional English belongs to real-time, involving the wide range of interdisciplinary courses, knowledge of computers and English disciplines are involved in computer-related fields, including computer hardware, software, network, etc. The objective of the course is the use of pre-and master English computer professional knowledge to learn computer-related technology better, the professional English course focuses primarily on students specialized vocabulary mastery and English read ability.

Teaching content is not focusing on specialized courses to learn English, which focuses on professional learning specialized vocabulary of English is different from other bilingual programs. Professional English can systematically learn the basic terminology and abbreviations, English expression in various disciplines such as computer, improve the professional level of English reading. The fundamental purpose of learning English is to improve computer focus their grasp of computer technology in the medium of English ability, so learning content should be launched around the professional field, should be the master professional learning vocabulary and terminology, understanding some of the computer specifications English translation law and customary usage $^{[1]}$.

Professional English can't be simply repeating already learned knowledge, but to improve the English proficiency. Professional English teaching practice shows that it can't simply repeat already learned the basics, otherwise the lack of freshness and student motivation. The main task of teaching mastery is to be placed in specialized vocabulary, reading and comprehension, writing on culture. The computer multimedia technique is applied in the physical education can provide high quality teaching software and relaxed teaching surroundings, help understand and grasp the knowledge comprehensively. According to the level and characteristics, the most teaching of the computer science undergraduates can be used as a separate course with appropriate individualized teaching. Because while the graduate computer science students already have basic English, the original English course books even can be a professional course books in teaching English.

\section{Status of Computer professional English Teaching}

Computer professional English is a required course of computer science related field. Its main task 
is to lay the necessary knowledge base of professional English for students of computer-related specialty, and to cultivate students' ability to read, understand and translate computer professional literature and professional knowledge. According to the survey of the status quo of college English teaching, the main problems of computer English teaching are as follows ${ }^{[2]}$. Fig.1 shows the status of computer professional English teach.

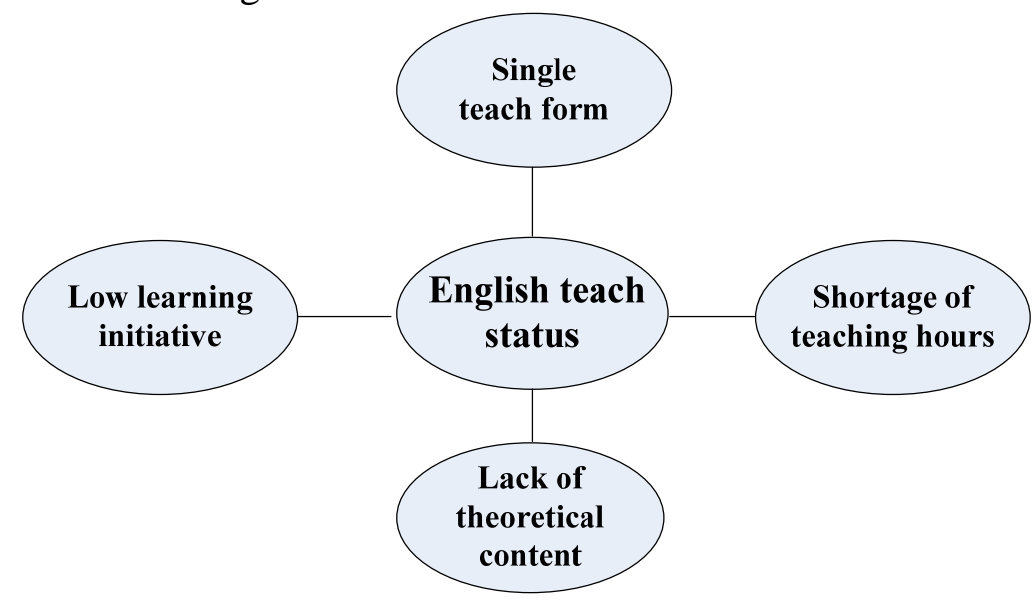

Fig. 1.The status of computer professional English teach

Courseware design should follow certain principles, focusing on interaction between students and teachers, students respect individual differences, different designs for different education situations. Most of the current professional English teaching methods using the traditional English teaching methods, that is, classroom teaching, translation, teaching methods mainly to "chalk + blackboard" or supplemented by multimedia projection equipment, teaching process lack of flexibility and fun, and ignored Student initiative and creativity. This kind of teaching way affects the effect of professional English teaching. Classroom teachers selected content textbooks should cover all aspects of the computer professional, both computer hardware knowledge, but also contains an introduction to use the software, programming, network-related technologies and moderate difficulty, and the other should be read with reference translation and CD.

The content of the teaching content is strong and the application is not enough. At present, the contents of the computer science teaching materials are mostly based on the branches of the computer science department, but ignore the practicality of the professional English. For example: textbooks introduced the field of computer software engineering theory, students do not know how to write and read software English documents, do not know the practical professional English. Computer major English is set up as an elective course in a part of the university. Even the required courses are arranged. The number of hours is limited. This determines that the learning content can only be limited to the teaching materials. Even if the teachers increase the extracurricular information, restrictions and can't achieve the desired results, so how to use the limited classroom time, the selection of teaching materials is also the key to improving the quality of teaching ${ }^{[3]}$.

\section{Teaching Reform of Computer Professional English}

Now the era has entered the Internet age, in addition to classroom teaching and student learning, you can learn to extend to the extracurricular, which can be achieved through the network platform. Teachers can develop learning sites, teaching resources on the network, so that students to share, through the online exchange to the students Q \& A, students can download these resources, you can also QQ, We Chat, E-mail and other means of communication with the teacher real-time communication, their learning experience, learning process encountered Difficult questions feedback to the teacher, to solve the problem in time ${ }^{[4]}$.

Through the network, teachers guide students to visit the resources around the world, especially in foreign learning sites, can broaden their horizons, enrich their knowledge, improve their English level, but also understand the forefront of the field of computer development knowledge. Teachers 
can be more pictures, audio, video material to the classroom up. The use of multimedia teaching model, to explain the knowledge more thoroughly, the classroom more lively and interesting, but also can effectively supplement the classroom knowledge. Through the reform of teaching methods and the application of new teaching model, students become the master of the classroom and become the organizers and participants of the classroom teaching activities. The students take the initiative to propose new teaching methods to the teachers. Through these teaching reform attempts, the whole classroom atmosphere is dynamic, and teaching effect is obviously improved.

The assessment of the course, we must start from the usual results, the attendance of students, the classroom to answer questions, the completion of the operation, usually with the teacher's communication record, included in the usual points of the end of the assessment can be heard, , To write four aspects of the assessment to complete the use of listening, oral, discussion, style and other innovative assessment methods to assess the final results of the final results given should pay attention to the usual assessment, the best usual results accounted for $60 \%-70 \%$, ending results accounted for $30 \%-40 \%$ is appropriate. Improve the teaching quality of teachers, improve the teaching methods, improve the students learning initiative, improve the teaching mode and improve the assessment methods and other aspects of the reform attempt to achieve a better teaching effect.

\section{The Internet Teaching Platform}

Learning platform via the Internet, learners can view various types of quality teaching resources, teachers can learners learning process, the number of online, long effective monitoring at logon, administrators can teaching activities Primary School to regulate guidance and better optimization classroom, so as to enhance the overall level. Although the Internet learning platform is more mature application platform, but its ongoing maintenance and functional expansion is still a top priority. Internet-based learning platform as the base camp, the platform, still needs to make further efforts in terms of cross-platform compatibility ${ }^{[5]}$. Fig.2 shows the Internet teaching platform.

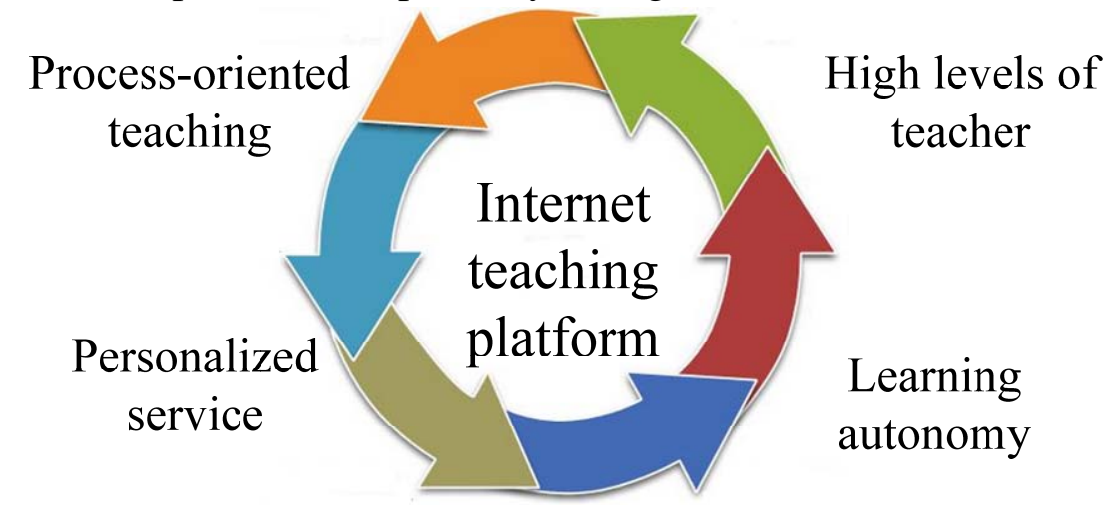

Fig. 2.The Internet teaching platform

Instructional design streamlined. Teaching process design according to the characteristics of each course, the teaching process need modular, each module teaching activities require concrete. Each module can only enter after learning tasks to complete the next learning module, in order to achieve the purpose to enhance learning. Through the process of instructional design, the learner can complete each course in accordance with the requirements step by step. Because of individual differences in the level of knowledge of learners, different learning requirements of learners, acceptance and achievable goals are different. To form a variety of hierarchical menus to learners alternative course guidelines, including an overview of the course, objectives, content, assessment plan, implementation of the recommendations, etc., in order to meet the individual and diverse teaching management. In addition, the platform can be developed for learners personalized content for learners' learning behavior data mining, to distinguish patterns of behavior of learners, learning preferences.

Independent learning learners, through the process of teaching, order management, individualized services and other measures to address the students' self-directed learning, self-monitoring, self-evaluation and other issues. Teaching management platform can also help 
learners to form correct self-learning method. Learners can be customized personalized service and subscribe to your attention the content according to their actual situation, truly autonomous learning. Distance education is a higher, more stringent requirement for teachers. Distance education teachers should not only have deep expertise, a broad range of scientific and cultural knowledge, but also has to help learners to self-monitoring and self-evaluation capabilities. Open University should be the selection, training a large number of outstanding teachers, enhance the core competitiveness of the school, which is also essential for teaching management ${ }^{[6]}$.

\section{Conclusions}

With the rapid advance of mufti-media and network technologies, web-based learning becomes possible. This new way of leaning can break the limit of traditional campus, and create a diverse learning environment that is not limited by time and space. In this paper, Network can make the learner more actively participate and feel more interested in the study itself. Computer professional English is learning specialized vocabulary to express and develop English proficiency, which is not exactly equivalent to the bilingual program. On the basis of teaching practice, analyzes the status quo prevailing English teaching computer science, because both the dual characteristics of specialized courses and English lessons, computers English course content, teaching resources and teaching activities have its own peculiarities in the organization of professional. We explore the professional English teaching model, and propose the idea computer professional English teaching reform.

\section{References}

[1] Yang Song, Song Le. Study and Practice of Computer English Teaching Reform [J]. Journal of Dalian Ocean University, 2011, 9 (3): 259-261.

[2] Pu Yan Li, Zhang Nan Reform of English Teaching methods Computer [J] Value Engineering, 2010 (7): 180-181.

[3] Dornyei, Z. (2013). Questionnaires in second language research: construction administration and processing, pp. 74-75. Lawrence Erlbaum Associates, Mahwah, NJ.

[4] Aaron Sams, Jonathan Bergmann. Flip Your Students' Learning [J] .Educational Leadership, 2013 (3).

[5] Xie Yan pan. English Teaching Course in Vocational College computer science [J] Beijing: Exam (teaching and research), 2015 (21): 16-17.

[6] Liu Mei. College English Teaching Reform of Computer Liu Mei vocational colleges [J] Haikou: teacher, 2015 (29): 35-39. 